\title{
вмJ Global Health Effect of low-dose versus higher-dose antenatal iron supplementation on child health outcomes at 36 months of age in Viet Nam: longitudinal follow-up of a cluster randomised controlled trial
}

\author{
Sarah Hanieh, ${ }^{1}$ Tran T Ha, ${ }^{2}$ Julie A Simpson, ${ }^{3}$ Sabine Braat, ${ }^{3}$ Tran T Thuy, ${ }^{2}$ \\ Thach D Tran, ${ }^{2,4}$ Janet King, ${ }^{5}$ Tran Tuan, ${ }^{2}$ Jane Fisher, ${ }^{4}$ Beverley-Ann Biggs ${ }^{1,6}$
}

To cite: Hanieh S, Ha TT, Simpson JA, et al. Effect of low-dose versus higher-dose antenatal iron supplementation on child health outcomes at 36 months of age in Viet Nam: longitudinal followup of a cluster randomised controlled trial. BMJ Glob Health 2017;2:e000368. doi:10.1136/ bmjgh-2017-000368

Received 11 April 2017 Revised 9 June 2017 Accepted 17 June 2017

CrossMark

For numbered affiliations see end of article.

Correspondence to

Sarah Hanieh;

shanieh@unimelb.edu.au

\section{ABSTRACT}

Introduction Intermittent iron-folic acid supplementation (IFA) is currently recommended for pregnant women in populations where anaemia prevalence among pregnant women is $<20 \%$ or if daily iron is not acceptable. The effect of providing lower doses of antenatal elemental iron through intermittent regimes on longer-term health outcomes in childhood is unclear.

Methods A prospective cohort study conducted between May 2012 and May 2014 in Viet Nam among children of 36 months of age, born to women previously enrolled in a cluster randomised controlled trial of antenatal micronutrient supplementation (daily IFA (60 mg elemental iron) vs twice-weekly IFA (60 mg elemental iron) vs twiceweekly multiple micronutrient (MMN) supplementation (60 mg elemental iron)). Primary outcomes were height-forage z-scores (HAZ), according to WHO growth standards and cognitive composite scores (Bayley Scales of Infant and Toddler Development, third edition) at 36 months of age.

Results A total of 1017 children born to mothers enrolled in the cluster randomised trial were assessed at 36 months of age. Adjusted mean differences (MDs) in HAZ were $-0.14(95 \% \mathrm{Cl}-0.28$ to -0.01$)$ and $-0.15(95 \% \mathrm{Cl}-0.29$ to -0.01) in children born to mothers who received twiceweekly IFA or MMN compared with those who received daily IFA. Children born to mothers who received twiceweekly MMN had lower composite motor scores compared with those who received daily IFA (MD $-2.07,95 \% \mathrm{Cl}$ -4.11 to -0.03 ). There were no differences in composite cognitive scores in the twice-weekly compared with daily regimens.

Conclusions Low-dose antenatal IFA supplementation (120 mg elemental iron per week) resulted in lower HAZ and motor composite scores in children compared with higher-dose antenatal IFA supplementation $(420 \mathrm{mg}$ elemental iron per week). This highlights the importance of adequate iron stores during pregnancy and the need for careful monitoring when lower-dose antenatal iron regimens are used.

Trial registration number Australia New Zealand Clinical Trials Registry: 12610000944033.

\section{INTRODUCTION}

Micronutrients play an important role in the health of mothers and children in resourcepoor settings where nutritional deficiencies are prevalent. ${ }^{1-3}$ WHO currently recommends the use of intermittent iron-folic acid (IFA) for pregnant women in populations where anaemia prevalence among pregnant women is $<20 \%$ or if daily iron is not acceptable due to side effects. ${ }^{45}$ Although the effect of intermittent IFA on maternal and neonatal outcomes has been previously described, ${ }^{67}$ the impact on longer-term health outcomes in childhood has not yet been reported.

We previously conducted a cluster randomised controlled trial (RCT) in which pregnant women received either daily IFA supplementation or twice-weekly iron or multiple micronutrient (MMN) supplementation. ${ }^{8}$ This was the largest RCT in a developing country setting to investigate the use of intermittent antenatal micronutrient regimens on infant outcomes past the neonatal period, and the first to compare daily IFA with intermittent MMN supplementation. We found no difference in birth weight between infants born to mothers in the twice-weekly IFA (mean difference (MD) $28 \mathrm{~g}, 95 \% \mathrm{CI}-22$ to 78 ) and MMN groups (MD $-36.8 \mathrm{~g}, 95 \% \mathrm{CI}-82$ to 8.2 ) compared with those in the daily IFA group; or height-for-age z-scores (HAZ) at 6 months of age between infants born to mothers in the twice-weekly IFA (MD-0.14, 95\% CI -0.29 to 0.02 ) and $\mathrm{MMN}$ groups (MD $-0.04,95 \% \mathrm{CI}$ -0.20 to 0.11 ) compared with those in the daily IFA group. However, infants of mothers who received twice-weekly IFA had composite cognitive scores that were 1.89 scores higher at 6 months of age compared with those who 


\section{Key questions}

\section{What is already known about this topic?}

- Pregnant women have increased nutrient needs, and deficiencies in essential nutrients during this period may result in adverse health outcomes for the mother and child.

- Intermittent iron-folic acid supplementation is currently recommended for pregnant women in populations where anaemia prevalence among pregnant women is $<20 \%$ or if daily iron is not acceptable.

- Lower cognitive scores have been previously described in infants born to women who received twice-weekly antenatal iron-folic acid supplements compared with those who received daily ironfolic acid supplements. However, there is minimal data on the impact of intermittent iron-folic acid supplementation on longerterm health outcomes in childhood.

\section{What are the new findings?}

- Children born to women who received twice-weekly iron-folic acid or multiple micronutrient supplementation during pregnancy (120 mg elemental iron per week) during pregnancy had lower height and height-for-age z-scores compared with those who received daily antenatal iron supplementation (420 mg elemental iron per week).

- Motor composite scores at 36 months of age were lower in children born to women who received antenatal multiple micronutrient supplementation compared with those who received antenatal daily iron-folic acid supplementation. No differences in composite cognitive scores of children born to mothers who received twice-weekly iron-folic acid compared with daily ironfolic acid supplementation was observed.

\section{Recommendations for policy}

- Continued efforts are required to ensure pregnant women in low-income settings have adequate iron stores during pregnancy.

- A better understanding of the long-term clinical outcomes in children born to mothers receiving low doses of iron during the pregnancy period is required

received daily IFA (95\% CI 0.23 to 3.56 ) when measured using the Bayley Scales for Infant and Toddler Development, third edition (BSID III).

Children born in the original RCT have now been followed up to 36 months of age, allowing investigation of whether antenatal IFA or MMN given twice weekly during pregnancy has a differential effect on child growth and developmental outcomes compared with daily IFA. Based on our findings at 6 months of age, we hypothesised that there would be no difference in HAZ in the children at 36 months of age, and that the minimal differences in infant cognitive scores between the daily and intermittent IFA groups would not persist. We also examined haemoglobin $(\mathrm{Hb})$ concentration, and serum ferritin, folate and vitamin B12 concentrations at 36 months of age.

\section{METHODS}

\section{Study design, setting and participants}

This prospective cohort study was conducted between May 2012 and May 2014, in Ha Nam province in rural North
Viet Nam. Viet Nam has experienced rapid social and economic development over the last 10 years; however, disparities in health and nutrition between the rich and poor have widened, with many children in rural areas still experiencing high rates of anaemia and stunting. ${ }^{9}$

The RCT has been previously described. ${ }^{8}$ Briefly, 1258 women from 104 communes in Ha Nam province were enrolled. Participants received supplements from enrolment (median 12 weeks gestation) until 3 months post partum, and were seen at enrolment, 32 weeks gestation, delivery, 6 weeks and 6 months post partum. Allocation was based on communes (clusters). The trial had three intervention groups: (1) one tablet of IFA taken daily (60 mg elemental iron (ferrous sulfate) plus $0.4 \mathrm{mg}$ folic acid per tablet, administered as seven tablets/week); (2) one capsule of IFA taken twice a week $(60 \mathrm{mg}$ elemental iron (ferrous sulfate) plus $1.5 \mathrm{mg}$ folic acid per capsule; administered as two capsules/week); or (3) one capsule of MMNs taken twice a week $(60 \mathrm{mg}$ elemental iron (ferrous sulfate) plus $1.5 \mathrm{mg}$ folic acid plus a variation of the dose of micronutrients in the United Nations Mutiple Micronutrient Preparation (UNIMAPP) supplement ${ }^{10}$; administered as two capsules/week). All supplements were manufactured by the local Nam Ha Pharmaceutical company (Nam Dinh, Viet Nam) (WHO Good Manufacturing Practice certified). A total of 1049 women and infants completed the trial and were seen by the research team at 6 months post partum (when infants were 6 months of age). All children born to mothers enrolled in the RCT were eligible to take part in the follow-up study. Children received no intervention during the first 36 months of life. Assessments were carried out at the commune health station at $6,12,18,24,30$ and 36 (final survey) months of age. The investigators, field staff and participants were blinded to the codes of the intermittent supplement groups throughout the study and during data analysis. Laboratory staff were unaware of the intervention groups. It was not possible to blind the field team to the daily supplementation arm, but participants were not informed about the dosing frequency of the intervention being given in other communes. An independent team undertook the BSID III assessments and were blinded to the intervention arms.

\section{Procedures}

Children born in the RCT were followed up until 36 months of age by the same local non-governmental organisation (RTCCD) which conducted the RCT. Research staff underwent repeat training in anthropometric measurements and development assessment with BSID III.

\section{Maternal information}

Maternal age, height, weight, education, occupation, and gravidity were collected in the RCT at enrolment.

\section{Socio-demographic information}

A questionnaire was administered to carers at the time of the 12-month survey (when children were formally 
enrolled in the cohort study), covering socioeconomic status (eg, type of toilet, main water and energy source).

\section{Anthropometric measurements}

Anthropometric measures (height and weight) were recorded at $6,12,18,24,30$ and 36 months of age. These measurements were made in triplicate, with a second observer checking all measurements for validity. The median measurement was used for analysis. Standing height was measured using a portable Shorr Board (Shorr Productions) with the child positioned with the heels touching the base of the stadiometer, knees and feet extended, and their head and back touching the stadiometer (footwear was removed). Weight was measured using electronic Seca 890 scales, with precision to the nearest $100 \mathrm{~g}$. Growth (height for age, weight for age and weight for height) was evaluated using the 2006 WHO Child Growth Standards. ${ }^{11}$ Anthropometric $z$-scores were calculated using WHO Anthro (V.3.2.2, January 2011). ${ }^{12}$ Being stunted, wasted or underweight was defined as having a z-score $<2$ Standard Deviations [SD] below WHO growth standards on height for age, weight for height or weight for age, respectively.

\section{Developmental outcomes}

Developmental assessments for cognitive, language and motor domains were conducted at 6 and 36 months of age using BSID III. Local community-based psychologists conducted the assessment, following training from a local Vietnamese expert. Mild cognitive delay was defined as a cognitive composite score of 1-2 SDs below the mean, moderate delay as $>2-3$ SDs below the mean and severe delay as $>3$ SDs below the mean.

\section{Laboratory outcomes}

Children had blood collected at 6 and 36 months of age by local phlebotomists from the Provincial Paediatric hospital. $\mathrm{Hb}(\mathrm{g} / \mathrm{dL})$ was measured using a portable photometer (HemoCue Hemoglobin Systems), and 1 $\mathrm{mL}$ of venous blood was collected for ferritin and vitamin B12 concentrations. Samples were frozen at $-20^{\circ} \mathrm{C}$ and transported to the Alfred Hospital, Melbourne, for testing. Serum B12 (pmol/L) and ferritin $(\mu \mathrm{g} / \mathrm{L})$ were analysed using a chemiluminescent microparticle assay (Architect ci16200; Abbott Diagnostics). Anaemia in children was defined as $\mathrm{Hb}<11.0 \mathrm{~g} / \mathrm{dL}$, iron deficiency as serum ferritin $<12 \mu \mathrm{g} / \mathrm{L}$, iron deficiency anaemia as $\mathrm{Hb}<11.0 \mathrm{~g} / \mathrm{dL}$ and ferritin $<12 \mu \mathrm{g} / \mathrm{L}$, and B12 deficiency as serum $\mathrm{B} 12<150 \mathrm{pmol} / \mathrm{L}$. No adjustment was made for inflammation or infection using $\mathrm{C}$ reactive protein.

\section{Statistical analysis}

The sample size was a result of the number of women in the original RCT, which was powered at $80 \%$ to detect an effect size of a difference in the primary outcome of mean birth weight of $100 \mathrm{~g}, \mathrm{Hb}$ of $6 \mathrm{~g} / \mathrm{dL}$ and HAZ of 0.3 at a two-sided significance level of $5 \%$. Data were analysed according to the group to which women were randomised, with those lost to follow-up excluded, that is, a complete-case analysis. In table 1 , the significance of the difference in proportions was tested using the $\chi^{2}$ test and in means using the Student's t-test. For continuous outcomes, linear mixed-effects models were used for repeated measures at $6,12,18,24,30$ and 36 months for HAZ; and at 6 and 36 months for developmental composite scores, $\mathrm{Hb}$, ferritin, folate and B12 concentrations, incorporating a random effect for child, both unadjusted (treatment only) and adjusted for maternal age (years), gravidity $(0,1-2, \geq 3)$, education (categories primary school, secondary school, university/college), body mass index (BMI), maternal pathology at 32 weeks gestation (for child laboratory outcomes) and clustering at the commune level. For binary outcomes assessed at 36 months of age, logistic regression was used, and unadjusted and adjusted odds ratios (ORs) are presented. Estimates (95\% CIs and associated $p$ value) of the effect (either difference in means or OR) between the daily (reference) and weekly trial groups at 36 months were extracted. No imputation of the missing data was performed for those lost to follow-up at the time of the 36-month survey. The linear mixed-effects model assumed missing data to be at most missing at random, using a likelihood-based approach to use the available data, while the logistic regression model assumed missing completely at random, deleting infants with no data at the 36-month assessment. The intracluster correlation coefficient for the HAZ at 36 months and cognitive development scores was 0.03 (95\% CI 0.00 to 0.06 ) and 0.02 (95\% CI 0.00 to 0.05 ), respectively. A stratified analysis to determine whether there was a different treatment effect for children of undernourished mothers at enrolment (BMI $<18.5 \mathrm{~kg}$ / $\mathrm{m}^{2}$ ) versus those with BMI $\geq 18.5$ on child anthropometric and developmental outcomes was explored. Associations between maternal ferritin concentration at 32 weeks gestation and child height, height for age and stunting outcomes at 36 months of age were explored using linear regression with estimates $(95 \%$ CIs) of the coefficient. Since ferritin and B12 concentrations were positively skewed, they were $\log$ base 2 transformed before analysis. All statistical analyses were performed using Stata, V.14. (StataCorp. 2015. Stata Statistical Software: Release 14. College Station, TX: StataCorp LP.)

\section{RESULTS}

Anthropometric and developmental outcomes were measured in 1017 children at 36 months of age. The trial profile is presented in figure 1. Retention rates (percentage of children seen at 36 months of age from live births) were $85.9 \%$ in the daily IFA group, $88.3 \%$ in the twice-weekly IFA group and $86.3 \%$ in the twiceweekly MMN group for the primary outcome of HAZ. Mean age at follow-up was 35.7 months, and this was similar in all groups. Table 1 compares maternal and household characteristics in the three groups at the 
Table 1 Maternal, household and child characteristics corresponding to children retained at 36 months $(n=1017)$ and of those lost to follow-up $(n=154)$

\begin{tabular}{|c|c|c|c|c|}
\hline & $\begin{array}{l}\text { Daily IFA* } \\
(n=336)\end{array}$ & $\begin{array}{l}\text { Twice-weekly IFA* } \\
(\mathrm{n}=353)\end{array}$ & $\begin{array}{l}\text { Twice-weekly MMN* } \\
(\mathrm{n}=328)\end{array}$ & $\begin{array}{l}\text { Lost to follow-up* } \\
(n=154)\end{array}$ \\
\hline \multicolumn{5}{|l|}{ Maternal characteristics } \\
\hline Height (cm) & $154.3[4.8]$ & $153.9[4.7]$ & $153.2[4.8]$ & $152.9[4.8]$ \\
\hline Body mass index $\left(\mathrm{kg} / \mathrm{m}^{2}\right)$ & 19.9 [1.95] & $19.8[1.9]$ & $19.9[2.0]$ & $19.8[2.2]$ \\
\hline Low $\left(<18.5 \mathrm{~kg} / \mathrm{m}^{2}\right)$ & $77(24.2)$ & $87(25.9)$ & $83(26.9)$ & $28(31.1)$ \\
\hline Normal $\left(18.5-25 \mathrm{~kg} / \mathrm{m}^{2}\right)$ & 239 (75.2) & $247(73.5)$ & 217 (70.2) & $60(66.7)$ \\
\hline High $\left(>25 \mathrm{~kg} / \mathrm{m}^{2}\right)$ & $2(0.6)$ & $2(0.6)$ & $9(2.9)$ & $2(2.2)$ \\
\hline \multicolumn{5}{|l|}{ Age (years) } \\
\hline$<20$ & $38(11.9)$ & $20(5.9)$ & $22(7.1)$ & $7(7.8)$ \\
\hline $20-29$ & $235(73.7)$ & 245 (72.9) & $229(74.1)$ & $67(74.4)$ \\
\hline$\geq 30$ & $46(14.4)$ & $71(21.1)$ & $58(18.8)$ & $16(17.8)$ \\
\hline \multicolumn{5}{|l|}{ Education† } \\
\hline Primary school & $53(15.5)$ & $42(11.9)$ & $60(18.1)$ & $27(17.4)$ \\
\hline Secondary school & $169(49.3)$ & $197(55.8)$ & $166(50.0)$ & $62(40.0)$ \\
\hline High school & $88(25.7)$ & $75(21.3)$ & $85(25.6)$ & $43(27.7)$ \\
\hline University/college & $33(9.6)$ & $39(11.1)$ & $21(6.3)$ & $23(14.8)$ \\
\hline \multicolumn{5}{|l|}{ Occupation† } \\
\hline Farmer & $140(40.8)$ & $151(42.8)$ & $143(43.1)$ & $43(27.7)$ \\
\hline Factory worker & $57(16.6)$ & $52(14.7)$ & $41(12.4)$ & $25(16.1)$ \\
\hline Trader & 58 (16.9) & 68 (19.3) & 63 (18.9) & $36(23.2)$ \\
\hline Government official & $31(9.0)$ & $44(12.5)$ & $25(7.5)$ & $26(16.7)$ \\
\hline Clerk & $17(5.0)$ & $10(2.8)$ & $13(3.9)$ & $5(3.2)$ \\
\hline Not in income-generating work & $38(11.1)$ & $22(6.2)$ & $41(12.4)$ & $17(10.9)$ \\
\hline Other & $2(0.6)$ & $6(1.7)$ & $6(1.8)$ & $3(1.9)$ \\
\hline \multicolumn{5}{|l|}{ Gravidity } \\
\hline 0 & $127(37.0)$ & $92(26.1)$ & $106(32.0)$ & $46(29.9)$ \\
\hline $1-2$ & $178(51.9)$ & $208(58.9)$ & $182(55.0)$ & $85(55.2)$ \\
\hline$\geq 3$ & $38(11.1)$ & $53(15.0)$ & $43(13.0)$ & $23(14.9)$ \\
\hline \multicolumn{5}{|l|}{ Nutritional status } \\
\hline \multicolumn{5}{|l|}{-At enrolment } \\
\hline Haemoglobin (g/dL) & $12.3[1.4]$ & $12.1[1.1]$ & $12.3[1.2]$ & $12.5[1.2]$ \\
\hline Ferritin ( $\mu \mathrm{g} / \mathrm{L})$ & $74.5\{47$ to 125$\}$ & $83\{54$ to 129$\}$ & $79\{49$ to 124$\}$ & $89\{49$ to 134$\}$ \\
\hline B12 (pmol/L) & $398\{319$ to 504$\}$ & $395.5\{319$ to 502$\}$ & $411\{323$ to 518$\}$ & $414\{329$ to 514$\}$ \\
\hline Folate (nmol/L) & $27.6\{21.0$ to 35.4$\}$ & $28.5\{21.4$ to 34.5$\}$ & $27.7\{21.3$ to 33.1$\}$ & $27.9\{20.9$ to 33.5$\}$ \\
\hline \multicolumn{5}{|l|}{-At 32 weeks gestation } \\
\hline Haemoglobin (g/dL) & $12.5[1.4]$ & $12.4[1.1]$ & $12.3[1.2]$ & $12.2[1.2]$ \\
\hline Ferritin $(\mu \mathrm{g} / \mathrm{L})$ & $35\{24.5$ to 55$\}$ & $27\{18$ to 37$\}$ & $22\{14$ to 35$\}$ & $25.5\{15$ to 38.5$\}$ \\
\hline $\mathrm{B} 12(\mathrm{pmol} / \mathrm{L})$ & $234\{186.5$ to 282.5$\}$ & $231.5\{188$ to 285$\}$ & $233\{190$ to 290$\}$ & $219.5\{175$ to 263.5$\}$ \\
\hline Folate (nmol/L) & $29.9\{24.0$ to 34.5$\}$ & $29.3\{24.5$ to 33.9$\}$ & $25.5\{17.9$ to 32.0$\}$ & $25.6\{18.5$ to 32.2$\}$ \\
\hline \multicolumn{5}{|l|}{ Household characteristics } \\
\hline \multicolumn{5}{|l|}{ Type of toilet } \\
\hline None & $2(0.6)$ & $2(0.6)$ & $12(3.7)$ & $2(3.6)$ \\
\hline Pit latrine & $48(14.5)$ & $57(16.2)$ & $46(14.2)$ & $4(7.1)$ \\
\hline Compartment latrine & $63(19.0)$ & 54 (15.4) & $50(15.4)$ & $6(10.7)$ \\
\hline
\end{tabular}


Table 1 Continued

\begin{tabular}{|c|c|c|c|c|}
\hline & $\begin{array}{l}\text { Daily IFA* } \\
(n=336)\end{array}$ & $\begin{array}{l}\text { Twice-weekly IFA* } \\
(n=353)\end{array}$ & $\begin{array}{l}\text { Twice-weekly MMN* } \\
(\mathrm{n}=328)\end{array}$ & $\begin{array}{l}\text { Lost to follow-up* } \\
(n=154)\end{array}$ \\
\hline Flush toilet & 216 (65.9) & $238(67.8)$ & $216(66.7)$ & 44 (78.6) \\
\hline \multicolumn{5}{|c|}{ Child characteristics } \\
\hline \multicolumn{5}{|l|}{ Sex } \\
\hline Male & 165 (51.7) & $184(54.8)$ & 159 (51.5) & $42(49.4)$ \\
\hline Female & 154 (48.3) & $152(45.2)$ & $150(48.5)$ & $43(50.6)$ \\
\hline Birth weight $(g) \dagger$ & 3156 [424] & 3186 [355] & 3137 [424] & 3065 [495] \\
\hline Preterm delivery† & 35 (10.6) & $39(11.4)$ & 41 (13.3) & 26 (17.9) \\
\hline
\end{tabular}

${ }^{*}$ Data are number (\%), mean [SD] or median $\{25$ th to 75 th centile $\}$.

IFA , iron-folic acid; MMN , multiple micronutrients.

12-month time point (when children were formally enrolled into the follow-up cohort study), and for 154 children who were lost to follow-up by 36 months of age. Secondary school was most often reported as the highest level of education and the majority of households used a flush toilet. Nearly $13 \%$ of children were delivered preterm. Women who were lost to follow-up were more likely to be university educated and working as government officials, and to have delivered a preterm infant with a lower birth weight.

\section{Growth outcomes}

Anthropometric outcomes were available on 1017 children at 36 months of age. Table 2 presents anthropometric indices by maternal antenatal supplement group at $6,12,18,24,30$ and 36 months of age. Analysis of child growth outcomes at 36 months is presented in table 3. The prevalence of stunting was $17 \%$ $(173 / 1017)$, wasting $1 \%(10 / 1017)$ and underweight $6.1 \%(62 / 1017)$. Average length/HAZ decreased over time in each of the groups. Two analyses are presented: (1) unadjusted analysis comparing MD between the intermittent groups (120 mg elemental iron per week) compared with the daily arm $(60 \mathrm{mg}$ elemental iron per week); and (2) analysis adjusted for maternal age, parity and education, maternal BMI and clustering. Mean height was $91.5 \mathrm{~cm}$ (SD 3.5) in the daily IFA group, $90.9 \mathrm{~cm}$ (SD 3.2) in the twice-weekly IFA group and $90.9 \mathrm{~cm}$ (SD 3.5) in the twice-weekly MMN group. Children born to mothers who received twice-weekly IFA during pregnancy (MD $-0.14,95 \%$ CI -0.28 to -0.01 ) or twice-weekly MMN during pregnancy (MD $-0.15,95 \%$ CI -0.29 to -0.01 ) were found to have significantly lower HAZ than children born to mothers who received daily IFA. No difference in the odds of stunting or underweight was observed in children born to mothers who received daily IFA versus twice-weekly IFA or MMN. No difference in the treatment effects on growth outcomes was found when children were stratified according to whether mothers were undernourished at enrolment $\left(\right.$ BMI $<18.5 \mathrm{~kg} / \mathrm{m}^{2}$ ) or not ( $\mathrm{p}=0.7$ and 0.4 for user-defined contrast of twice-weekly
IFA and twice-weekly MMN vs daily IFA respectively). There was no association between maternal ferritin concentration at 32 weeks gestation and child HAZ at 36 months of age (figure 2).

\section{Development}

Mean cognitive development scores at 36 months of age were 96.3 (SD 6.7) in the daily IFA arm, 96.2 (SD 4.8 ) in the twice-weekly IFA arm and 96.0 (SD 5.51) in the twice-weekly MMN arm. Mild cognitive delay was found in $23.8 \%$, moderate delay in $0.2 \%$ and severe delay in $0.1 \%$ of children. There was no difference in the cognitive scores of children born to mothers who received twice-weekly IFA (MD $-0.19,95 \%$ CI -1.20 to 0.82 ) or twice-weekly MMN (MD $-0.26,95 \%$ CI -1.24 to 0.72 ) during pregnancy, compared with those whose mothers received daily IFA. Lower composite motor scores were seen in the children born to women who received twice-weekly MMN compared with those whose mothers received daily IFA (MD $-2.07,95 \%$ CI -4.11 to -0.03 ) (Table 4). None of the development domains provided evidence of a different treatment effect for children born to mothers who were undernourished at enrolment (BMI $<18.5 \mathrm{~kg} / \mathrm{m}^{2}$ ) compared with those who were not.

\section{Haemoglobin and micronutrient outcomes}

Overall mean $\mathrm{Hb}$ at 36 months of age was 11.7 (SD $0.96)$ and $18.6 \%(180 / 966)$ of children were found to be anaemic. The unadjusted and adjusted analyses are shown in table 5. There was no difference in mean $\mathrm{Hb}$ or odds of anaemia in children born to women who received twice-weekly IFA or twice-weekly MMN supplements compared with those born to women who received daily IFA. Overall median ferritin concentration was $35 \mu \mathrm{g} / \mathrm{L}$ (25th to 75 th percentile 21-54) and 4.4\% (37/845) of children were iron deficient. No difference in ferritin concentration and iron deficiency status at 36 months of age was demonstrated between the weekly versus daily supplementation groups. Only 1\% (9/838) children had iron deficiency anaemia. Overall median vitamin B12 concentration was 514 (25th to 75 th percentile $400-673$ ) 


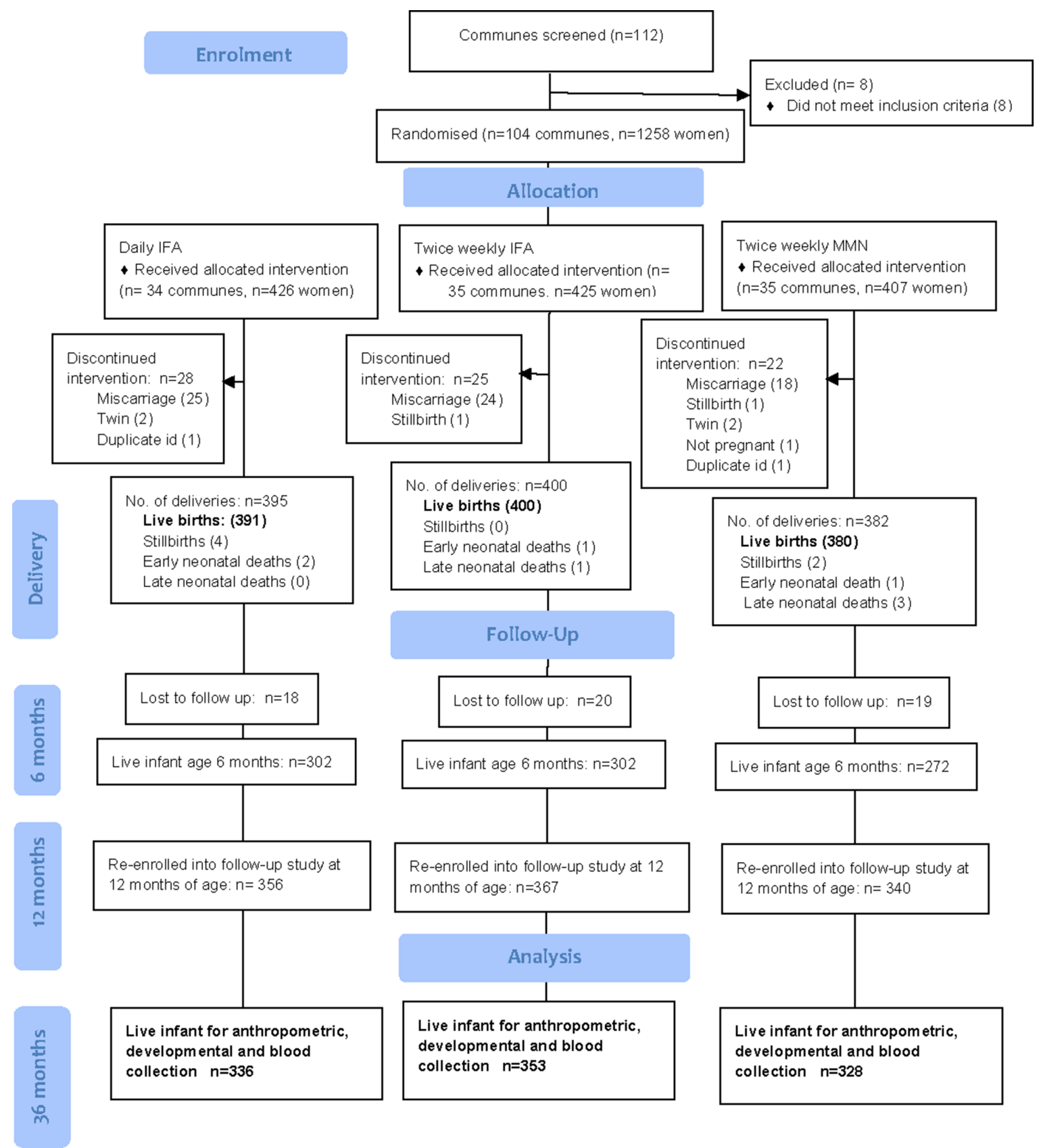

Figure 1 Flow diagram. IFA, iron-folic acid; MMN, multiple micronutrients.

and no infants were vitamin B12 deficient. There was no difference in vitamin B12 concentration between children born to women who received the twice-weekly supplements compared with those born to women who received daily supplementation (table 5 ).

\section{DISCUSSION}

To our knowledge, this is the first RCT investigating the use of low-dose (120 mg per week) versus higher-dose (420 mg per week) antenatal iron supplementation regimens to determine clinical outcomes in children to 36 months of age. We found that children born to mothers who received intermittent iron supplementation during pregnancy (120 mg elemental iron per week) had significantly lower height and HAZ than children born to mothers who received daily antenatal IFA (420 mg elemental iron per week). Furthermore, motor development scores were lower in children whose mothers received twice-weekly IFA or MMN during pregnancy compared with daily IFA. There were no differences in stunting, wasting, underweight, $\mathrm{Hb}$ or micronutrient concentrations between the different antenatal supplement groups.

The finding that antenatal IFA supplementation given daily has a beneficial effect on child growth at 36 months of age compared with twice-weekly supplementation may reflect the important role that maternal iron status plays in fetal growth, ${ }^{13}$ in addition to potential epigenetic 
Table 2 Anthropometric indices at 6, 12, 18, 24, 30 and 36 months of age by maternal antenatal supplement group $(n=1017)$

\begin{tabular}{|c|c|c|c|c|}
\hline & Children with data (n, \%) & Daily IFA* & Twice-weekly IFA* & Twice-weekly MMN* \\
\hline \multicolumn{5}{|l|}{6 months } \\
\hline Length-for-age z-score & $1046(89.3)$ & $-0.52[0.9]$ & $-0.65[0.9]$ & $-0.56[1.0]$ \\
\hline Weight-for-age z-score & $1049(89.6)$ & $-0.09[1.0]$ & $-0.12[1.0]$ & $-0.11[3.9]$ \\
\hline Weight-for-height z-score & $1046(89.3)$ & $0.36[1.0]$ & $0.44[1.02]$ & $0.38[1.02]$ \\
\hline Wasting & $1046(89.3)$ & $5(1.4)$ & $3(0.8)$ & $7(2.1)$ \\
\hline Underweight & $1049(89.6)$ & $10(2.9)$ & $14(3.9)$ & $11(3.3)$ \\
\hline Stunted & $1046(89.3)$ & $23(6.6)$ & $22(6.1)$ & $22(6.6)$ \\
\hline \multicolumn{5}{|l|}{12 months } \\
\hline Length-for-age z-score & $1021(87.2)$ & $-0.69[1.0]$ & $-0.75[0.9]$ & $-0.77[1.0]$ \\
\hline Weight-for-age z-score & $1021(87.2)$ & $-0.39[1.0]$ & $-0.51[0.9]$ & $-0.46[1.0]$ \\
\hline Weight-for-height z-score & 1020 & $-0.11[1.0]$ & $-0.22[0.9]$ & $-0.13[1.0]$ \\
\hline Wasting & $1020(87.1)$ & $7(2.1)$ & $8(2.2)$ & $5(1.5)$ \\
\hline Underweight & $1021(87.2)$ & $17(5.0)$ & $19(5.3)$ & $20(6.2)$ \\
\hline Stunted & $1021(87.2)$ & $29(8.6)$ & $31(8.6)$ & $34(10.5)$ \\
\hline \multicolumn{5}{|l|}{18 months } \\
\hline Length-for-age z-score & $1032(88.1)$ & $-0.92[1.1]$ & $-1.05[0.9]$ & $-1.01[1.0]$ \\
\hline Weight-for-age z-score & $1037(88.6)$ & $-0.43[1.1]$ & $-0.55[0.9]$ & $-0.51[1.0]$ \\
\hline Weight-for-height z-score & $1032(88.1)$ & $0.01[1.0]$ & $-0.07[0.9]$ & $-0.03[0.9]$ \\
\hline Wasting & $1032(88.1)$ & $5(1.5)$ & $4(1.1)$ & $3(0.9)$ \\
\hline Underweight & $1037(88.6)$ & $21(6.1)$ & $15(4.2)$ & $21(6.3)$ \\
\hline Stunted & $1032(88.1)$ & $51(14.9)$ & $58(16.2)$ & $50(15.1)$ \\
\hline \multicolumn{5}{|l|}{24 months } \\
\hline Length-for-age z-score & 909 (77.6) & $-0.98[1.0]$ & $-1.05[0.91]$ & $-1.05[0.9]$ \\
\hline Weight-for-age z-score & 909 (77.6) & $-0.62[1.0]$ & $-0.68[0.89]$ & $-0.64[0.9]$ \\
\hline Weight-for-height z-score & $909(77.6)$ & $-0.18[1.0]$ & $-0.20[0.87]$ & $-0.14[0.8]$ \\
\hline Wasting & $909(77.6)$ & $6(1.9)$ & $6(1.9)$ & $5(1.7)$ \\
\hline Underweight & 909 (77.6) & $25(8.1)$ & $18(5.7)$ & $20(6.9)$ \\
\hline Stunted & 909 (77.6) & $43(13.9)$ & $46(14.7)$ & $43(15.0)$ \\
\hline \multicolumn{5}{|l|}{30 months } \\
\hline Height-for-age z-score & $1025(87.5)$ & $-1.03[0.9]$ & $-1.17[0.9]$ & $-1.15[0.9]$ \\
\hline Weight-for-age z-score & $1024(87.4)$ & $-0.56[0.9]$ & $-0.73[0.9]$ & $-0.65[1.0]$ \\
\hline Weight-for-height z-score & 1024 & $-0.02[0.9]$ & $-0.16[0.8]$ & $-0.01[0.9]$ \\
\hline Wasting & $1024(87.4)$ & $3(0.9)$ & $5(1.4)$ & $4(1.2)$ \\
\hline Underweight & $1024(87.4)$ & $15(4.4)$ & $25(7.0)$ & $25(7.6)$ \\
\hline Stunted & $1025(87.5)$ & $52(15.3)$ & $60(16.9)$ & $55(16.7)$ \\
\hline \multicolumn{5}{|l|}{36 months } \\
\hline Height-for-age z-score & 1017 (86.8) & $-1.04[0.9]$ & $-1.21[0.84]$ & -1.19 [0.92] \\
\hline Weight-for-age z-score & $1017(86.8)$ & $-0.53[0.9]$ & $-0.71[0.84]$ & $-0.66[0.95]$ \\
\hline Weight-for-height z-score & 1017 & $-0.05[0.9]$ & $-0.07[0.82]$ & $-0.01[0.88]$ \\
\hline Wasting & $1017(86.6)$ & $1(0.3)$ & $5(1.4)$ & $4(1.2)$ \\
\hline Underweight & $1017(86.6)$ & $17(5.1)$ & $22(6.2)$ & $23(7.0)$ \\
\hline Stunted & $1017(86.6)$ & 55 (16.4) & $60(17.0)$ & $58(17.7)$ \\
\hline
\end{tabular}

${ }^{*}$ Data are mean [SD] or number (\%).

IFA, iron-folic acid; MMN, multiple micronutrients.

changes during this period. ${ }^{14}$ The lack of association between maternal ferritin at 32 weeks gestation and child growth at 36 months of age raises the possibility that robust in utero iron concentrations are most critical in the early stages of pregnancy, for optimal postnatal child growth outcomes. Rapid fetal growth begins from 9 weeks after conception, and poor maternal nutritional status during the first trimester may have a significant impact 
Table 3 Descriptive statistics and analysis of child anthropometry at 36 months of age by treatment group, with unadjusted and adjusted models $(n=1017)$

\begin{tabular}{|c|c|c|c|}
\hline Anthropometric index & Values at 36 months* & $\begin{array}{l}\text { Unadjusted model } \\
\text { effect }+(95 \% \mathrm{Cl})\end{array}$ & $\begin{array}{l}\text { Adjusted model } \\
\text { effect } \dagger, \ddagger \text {, } \$(95 \% \mathrm{Cl})\end{array}$ \\
\hline \multicolumn{4}{|l|}{ Height (cm) } \\
\hline Daily IFA & 91.5 [3.5] & Reference & Reference \\
\hline Twice weekly IFA & 90.9 [3.2] & $-0.53 \S(-1.05$ to -0.01$)$ & $-0.55 \S(-0.72$ to -0.04$)$ \\
\hline Twice weekly MMN & 90.9 [3.5] & $-0.56 \S(-1.10$ to -0.02$)$ & $-0.59 \S(-1.13$ to -0.04$)$ \\
\hline \multicolumn{4}{|l|}{ Weight (g) } \\
\hline Daily IFA & $13.3[1.7]$ & Reference & Reference \\
\hline Twice-weekly IFA & $12.9[1.4]$ & $-0.26 \S(-0.52$ to -0.01$)$ & $-0.24(-0.49$ to 0.01$)$ \\
\hline Twice-weekly MMN & $13.1[1.6]$ & $-0.22(-0.48$ to 0.04$)$ & $-0.23(-0.49$ to 0.02$)$ \\
\hline \multicolumn{4}{|l|}{ Height-for-age z-score } \\
\hline Daily IFA & $-1.04[0.9]$ & Reference & Reference \\
\hline Twice-weekly IFA & $-1.21[0.8]$ & $-0.16 \S(-0.30$ to -0.03$)$ & $-0.14 \S(-0.28$ to -0.01$)$ \\
\hline Twice-weekly MMN & $-1.19[0.9]$ & $-0.15 \S(-0.29$ to -0.01$)$ & $-0.15 \S(-0.29$ to -0.01$)$ \\
\hline \multicolumn{4}{|l|}{ Weight-for-height z-score } \\
\hline Daily IFA & $0.04[0.95]$ & Reference & Reference \\
\hline Twice-weekly IFA & $-0.07[0.82]$ & $-0.11(-0.29$ to 0.03$)$ & $-0.08(-0.24$ to 0.08$)$ \\
\hline Twice-weekly MMN & $-0.01[0.88]$ & $-0.07(-0.22$ to 0.09$)$ & $-0.05(-0.21$ to 0.10$)$ \\
\hline \multicolumn{4}{|l|}{ Weight-for-age z-score } \\
\hline Daily IFA & $-0.53[0.97]$ & Reference & Reference \\
\hline Twice-weekly IFA & $-0.71[0.84]$ & $-0.17 \S(-0.32$ to -0.02$)$ & $-0.13(-0.28$ to 0.02$)$ \\
\hline Twice-weekly MMN & $-0.66[0.95]$ & $-0.13(-0.29$ to 0.03$)$ & $-0.12(-0.27$ to 0.04$)$ \\
\hline \multicolumn{4}{|l|}{ Stunting } \\
\hline Daily IFA & $55(16.4)$ & Reference & Reference \\
\hline Twice-weekly IFA & $60(17.0)$ & 1.05 (0.69 to 1.59$)$ & 0.99 (0.66 to 1.51) \\
\hline Twice-weekly MMN & $58(17.7)$ & $1.10(0.72$ to 1.67$)$ & 1.07 (0.70 to 1.64$)$ \\
\hline \multicolumn{4}{|l|}{ Underweight } \\
\hline Daily IFA & $17(5.1)$ & Reference & Reference \\
\hline Twice-weekly IFA & $22(6.2)$ & 1.25 (0.66 to 2.34$)$ & 1.18 (0.71 to 2.87$)$ \\
\hline Twice-weekly MMN & $23(7.0)$ & 1.42 (0.76 to 2.62$)$ & 1.43 (0.71 to 2.89$)$ \\
\hline
\end{tabular}

*Data are mean [SD] or number (\%).

†Effect is difference in means for height, weight, height-for-age z-score, weight -for-height- $z$ score, weight-for-age $z$ score and OR for stunting and underweight.

$\ddagger$ Adjusted for maternal age, parity, maternal education, maternal body mass index and clustering.

$\S p<0.05$.

IFA, iron-folic acid; MMN, multiple micronutrients.

on placental function and consequently fetal growth. ${ }^{15}$ We cannot rule out that children born to mothers who received daily antenatal IFA were different in other ways to those born to women receiving twice-weekly supplementation. However, this is unlikely as the study was randomised and extensive measurement of confounders was undertaken.

Eight other trials of antenatal/prenatal micronutrient supplementation have assessed growth in childhood; ${ }^{16-23}$ however, findings are inconsistent and none of these studies assessed intermittent supplementation regimens, where the total dose of iron given during pregnancy is significantly lower than in daily regimens. Two of these trials showed an improvement in growth outcomes in children born to mothers who took daily IFA compared with daily MMN or placebo. Khan et al found that MMN supplementation in pregnancy resulted in 5\% more stunting than IFA alone during the first five years of life. HAZ were also lower in the MMN group compared with the IFA group; however, this did not reach significance. ${ }^{17}$ Stewart et al found that children born to women who received daily IFA combined with zinc supplementation during pregnancy had greater postnatal linear growth $(0.65 \mathrm{~cm})$ at 7.5 years of age than control groups. ${ }^{19} \mathrm{In}$ contrast, Vadiya et al found that children born to women who took daily antenatal MMN had an increase of $204 \mathrm{~g}$ 


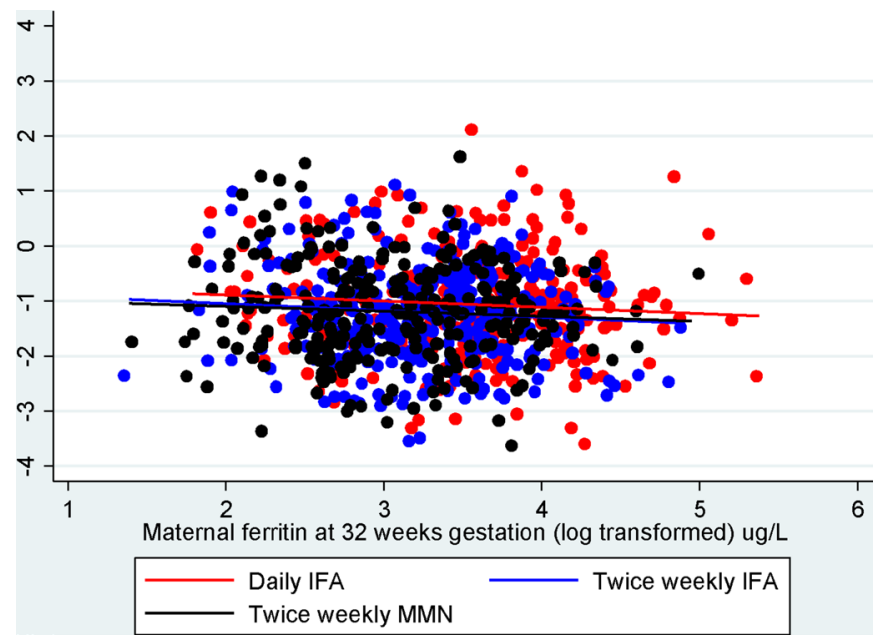

Figure 2 Scatter plot including linear fit showing relationship between maternal ferritin at 32 weeks gestation $(\log 2(\mu \mathrm{g} / \mathrm{L}))$ and child height-for-age z-scores at 36 months of age $(n=1017)$. The slopes of the lines are close to zero with $95 \% \mathrm{Cl}$. IFA, iron-folic acid; MMN, multiple micronutrients.

in weight and body size at 2.5 years of age compared with children born to women who received daily IFA. ${ }^{21}$ The other five trials showed no sustained difference in growth outcomes in children receiving daily IFA, daily MMN or placebo (folic acid). ${ }^{16} 18202223$

In our original RCT, we observed a two point difference in mean cognitive composite scores at 6 months of age between infants born to women who received twiceweekly IFA group compared with those who received daily IFA. This difference was not sustained at 36 months of age and may have been transient, or due to difficulties in cognitive testing of infants at 6 months of age. The finding that children born to women who received intermittent antenatal IFN or MMN supplementation had lower motor composite scores than those whose mothers received daily IFA may be explained by a higher iron concentration in utero in women who received daily IFA, associated with neurochemical changes related to the development of the motor system, such as improvement in neurotransmitters, dendritic branching, connections and myelination. ${ }^{24}$

Six other trials of antenatal/prenatal micronutrient supplementation have followed up cohorts into childhood to assess long-term developmental outcomes. ${ }^{2325-29}$ Our findings of an impact of antenatal IFA supplementation on child developmental outcomes support the results reported by Christian et al, who found that aspects of intellectual functioning (working memory, inhibitory control and fine motor functioning) among offspring aged 7-9 years in rural Nepal were positively associated with prenatal iron/folic acid supplementation. ${ }^{26}$ The other studies have found no impact of antenatal/prenatal micronutrient supplementation on child developmental outcomes. ${ }^{23252728}$ Several studies have shown that when pregnant women are undernourished or anaemic, provision of antenatal MMN supplements can improve the motor and cognitive abilities of their children up to 3.5 years later, particularly for both motor function and visual attention/spatial ability. ${ }^{27}{ }^{28}$ This is in contrast to our study in which no differential effects were observed in children born to undernourished women.

A systematic review and meta-analysis for long-term health benefits in children born to mothers who received

Table 4 Descriptive statistics and analysis of child development at 36 months of age by treatment group, with an adjusted model for differences between group means $(n=1017)$

\begin{tabular}{|c|c|c|c|c|}
\hline Developmental domain & $\begin{array}{l}\text { Values* } \\
6 \text { months }\end{array}$ & $\begin{array}{l}\text { Values* } \\
36 \text { months }\end{array}$ & $\begin{array}{l}\text { Unadjusted model } \\
\text { effect† }(95 \% \mathrm{Cl})\end{array}$ & $\begin{array}{l}\text { Adjusted model } \\
\text { effect } \dagger, \ddagger(95 \% \mathrm{Cl})\end{array}$ \\
\hline \multicolumn{5}{|l|}{ Cognitive } \\
\hline Daily IFA & $100.2[11.4]$ & $96.3[6.7]$ & Reference & Reference \\
\hline Twice-weekly IFA & $102.1[10.9]$ & $96.2[4.8]$ & $-0.15(-1.16$ to 0.86$)$ & $-0.19(-1.20$ to 0.82$)$ \\
\hline Twice-weekly MMN & $100.9[9.9]$ & $96.1[5.5]$ & $-0.28(-1.27$ to 0.70$)$ & $-0.26(-1.24$ to 0.72$)$ \\
\hline \multicolumn{5}{|l|}{ Language } \\
\hline Daily IFA & $94.0[8.0]$ & $105.5[9.2]$ & Reference & Reference \\
\hline Twice-weekly IFA & $94.8[8.2]$ & $104.2[8.5]$ & $-1.38(-3.36$ to 0.59$)$ & $-1.32(-3.24$ to 0.60$)$ \\
\hline Twice-weekly MMN & $94.8[7.7]$ & $104.5[8.2]$ & $-1.04(-2.76$ to 0.68$)$ & 0.98 (-2.68 to 0.71$)$ \\
\hline \multicolumn{5}{|l|}{ Motor } \\
\hline Daily IFA & $112.3[18.2]$ & 110.8 [11.9] & Reference & Reference \\
\hline Twice-weekly IFA & $113.4[18.9]$ & $109.5[10.6]$ & $-1.33(-3.56$ to 0.90$)$ & $-1.44(-3.65$ to 0.77$)$ \\
\hline Twice-weekly MMN & $112.5[18.4]$ & $108.9[10.6]$ & $-2.06(-4.16$ to 0.04$)$ & $-2.07 \S(-4.11$ to -0.03$)$ \\
\hline
\end{tabular}

${ }^{*}$ Data are mean [SD] .

†Effect is difference in means .

$\ddagger$ Adjusted for maternal age, parity, maternal education, maternal body mass index and clustering.

$\S \mathrm{p}<0.05$.

IFA, iron-folic acid; MMN, multiple micronutrient. 
Table 5 Descriptive statistics and analysis of child laboratory outcomes at 36 months by treatment group, with adjusted and unadjusted models $(n=1017)$

\begin{tabular}{|c|c|c|c|c|}
\hline Laboratory outcomes & $\begin{array}{l}\text { Values } \\
32 \text { weeks gestation* }\end{array}$ & $\begin{array}{l}\text { Values } \\
36 \text { months* }\end{array}$ & $\begin{array}{l}\text { Unadjusted model } \\
\text { effect† }(95 \% \mathrm{Cl})\end{array}$ & $\begin{array}{l}\text { Adjusted model } \\
\text { effect† }(95 \% \mathrm{Cl})\end{array}$ \\
\hline \multicolumn{5}{|l|}{ Haemoglobin (g/dL) } \\
\hline Daily IFA & $12.4[1.2]$ & $11.7[0.9]$ & Reference & Reference \\
\hline Twice-weekly IFA & $12.4[1.2]$ & $11.7[0.9]$ & $0.05(-0.10$ to 0.19$)$ & 0.09 (-0.06 to 0.25$)$ \\
\hline Twice-weekly MMN & $12.3[1.2]$ & $11.7[1.0]$ & $0.01(-0.21$ to 0.22$)$ & $0.01(-0.20$ to 0.22$)$ \\
\hline \multicolumn{5}{|l|}{ Anaemia $(\mathrm{Hb}<11.0 \mathrm{~g} / \mathrm{dL})$} \\
\hline Daily IFA & 35/344 (10.2) & $58(18.1)$ & Reference & Reference \\
\hline Twice-weekly IFA & $33 / 361(9.1)$ & $62(18.5)$ & 1.03 (0.69 to 1.53$)$ & 1.02 (0.67 to 1.56$)$ \\
\hline Twice-weekly MMN & 42/318 (13.2) & $60(19.3)$ & 1.08 (0.65 to 1.80$)$ & $1.08(0.65$ to 1.79$)$ \\
\hline \multicolumn{5}{|l|}{ Ferritin $(\mu \mathrm{g} / \mathrm{L}) \ddagger$} \\
\hline Daily IFA & $32\{24$ to 55$\}$ & $35\{21$ to 55$\}$ & Reference & Reference \\
\hline Twice-weekly IFA & $26\{18$ to 37$\}$ & $35\{21$ to 52$\}$ & $0.08(-0.07$ to 0.22$)$ & 0.07 (-0.08 to 0.22$)$ \\
\hline Twice-weekly MMN & $21\{14$ to 34$\}$ & $35.5\{20$ to 53.5$\}$ & $0.01(-0.15$ to 0.18$)$ & $0.01(-0.25$ to 0.18$)$ \\
\hline \multicolumn{5}{|l|}{$\begin{array}{l}\text { Iron deficiency } \\
\text { (ferritin<12 } \mu \mathrm{g} / \mathrm{L} \text { ) }\end{array}$} \\
\hline Daily IFA & $3 / 342(0.9)$ & $12(4.3)$ & Reference & Reference \\
\hline Twice-weekly IFA & $8 / 361(2.2)$ & $10(3.4)$ & 0.79 (0.31 to 2.04$)$ & 0.92 (0.35 to 2.40$)$ \\
\hline Twice-weekly MMN & 19/315 (6.0) & $15(5.6)$ & 1.31 (0.63 to 2.71$)$ & 1.49 (0.65 to 3.41$)$ \\
\hline \multicolumn{5}{|l|}{ B12 (pmol/L)‡ } \\
\hline Daily IFA & $230.5\{184$ to 279$\}$ & $530\{405$ to 678$\}$ & Reference & Reference \\
\hline Twice-weekly IFA & $229\{187$ to 285$\}$ & $512\{392$ to 680$\}$ & $-0.01(-0.10$ to 0.09$)$ & $-0.01(-1.0$ to 0.10$)$ \\
\hline Twice-weekly MMN & $233\{187$ to 287.5$\}$ & $502\{405$ to 650.5$\}$ & $0.02(-0.08$ to 0.11$)$ & $0.02(-0.07$ to 0.11$)$ \\
\hline
\end{tabular}

${ }^{*}$ Data are mean [SD], number (\%) or median $\{25$ th to 75 centile\}.

†Effect is difference in means for haemoglobin, ferritin and B12 and OR for anaemia and iron deficiency.

łLog base 2 transformed for statistical analysis.

$\S$ Adjusted for maternal age, parity, maternal education, maternal body mass index, maternal pathology at 32 weeks and clustering.

IFA, iron-folic acid; MMN, multiple micronutrients.

daily MMN supplementation compared with daily IFA or placebo during pregnancy found no consistent differences in HAZ, weight-for-age z-scores or cognitive scores. ${ }^{30}$

The strengths of our study are the relatively small proportion of children lost to follow-up, the large sample size and comprehensive measurements (including micronutrient status) collected on all participants. Limitations include the lack of measurement of other markers of body composition in children such as skin fold thickness and mid-upper arm circumference, and no control group (with no iron supplements given) in the original trial. Several outcome measures were investigated; therefore, the association that we observed of lower composite motor scores in children born to women who received twice-weekly MMN compared with those who received daily IFA may be due to type I error. The mothers of the $154(15 \%)$ children lost to follow-up were disproportionately more likely to come from a higher-educated, betterpaying job, which may have introduced bias. Our findings are likely to be generalisable to other rapidly developing rural areas in Viet Nam, as well as low-income and middle-income countries undergoing economic transition.

\section{CONCLUSION}

Low-dose iron supplementation given during pregnancy (120 mg per week) resulted in lower height and HAZ and motor composite scores in children at 36 months of age compared with high-dose antenatal iron supplementation ( $420 \mathrm{mg}$ per week) in this semirural setting in Viet Nam. These findings support the importance of adequate iron stores during pregnancy, and the need for long-term follow-up studies of clinical outcomes in children born to mothers receiving lower doses of iron during the antenatal period.

\section{Author affiliations}

${ }^{1}$ Department of Medicine, University of Melbourne, Peter Doherty Institute for Immunity and Infection, Parkville, Victoria, Australia

${ }^{2}$ Research and Training Centre for Community Development, Hanoi, Viet Nam ${ }^{3}$ Centre for Epidemiology and Biostatistics, Melbourne School of Population and Global Health, University of Melbourne, Melbourne, Victoria, Australia

${ }^{4}$ The Jean Hailes Research Unit, School of Public Health and Preventive Medicine, Monash University, Melbourne, Victoria, Australia

${ }^{5}$ Children's Hospital Oakland Research Institute, Oakland, California, USA

${ }^{6}$ The Victorian Infectious Diseases Service, Royal Melbourne Hospital, Parkville, Victoria, Australia 
Acknowledgements The authors thank the participants and health workers in Hanam province, the Hanam Provincial Centre of Preventive Medicine, Ministry of Health, RTCCD; Alfred Pathology; BethHilton-Thorpe and Christalla Hajisava.

Contributors SH analysed the data, prepared the results and wrote the first and subsequent drafts of the manuscript. SH, B-AB, TTH and JF designed the study. $\mathrm{SH}, \mathrm{TTH}$ and SB managed the data set and performed the statistical analysis. TTT, TDT, TTH, JAS and JK contributed to the study and survey design, reviewed and commented on the drafts of the report. TTH and TTG facilitated the conduct of the survey at the commune health stations. All authors approved the final submitted version of the manuscript. SH had full access to all the data in the study and assumes final responsibility for the decision to submit for publication.

Funding The original cluster randomised trial was funded through a grant from the National Health and Medical Research Council of Australia (grant number 628751).

Disclaimer The funders had no role in study design, data collection and analysis, decision to publish or preparation of the manuscript.

Competing interests $\mathrm{SH}$ is funded by an Australian National Health and Medical Research Council (NHMRC) Early Career Fellowship 1112581. JAS is funded by an Australian National Health and Medical Research Council (NHMRC) Senior Research Fellowship 1104975.

Ethics approval The Melbourne Health Human Research Ethics Committee and the Ha Nam Provincial Human Research Ethics Committee.

Provenance and peer review Not commissioned; externally peer reviewed.

Data sharing statement № additional data are available.

Open Access This is an Open Access article distributed in accordance with the Creative Commons Attribution Non Commercial (CC BY-NC 4.0) license, which permits others to distribute, remix, adapt, build upon this work non-commercially, and license their derivative works on different terms, provided the original work is properly cited and the use is non-commercial. See: http://creativecommons.org/ licenses/by-nc/4.0/

(c) Article author(s) (or their employer(s) unless otherwise stated in the text of the article) 2017. All rights reserved. No commercial use is permitted unless otherwise expressly granted.

\section{REFERENCES}

1. Black MM. Micronutrient deficiencies and cognitive functioning. $J$ Nutr 2003;133:3927s-31.

2. Black RE, Allen LH, Bhutta ZA, et al. Maternal and child undernutrition: global and regional exposures and health consequences. Lancet 2008;371:243-60.

3. Haider BA, Bhutta ZA. Multiple-micronutrient supplementation for women during pregnancy. Cochrane Database Syst Rev 2017;4:CD004905.

4. World Health Organisation. Intermittent iron and folic acid supplementation during pregnancy. secondary intermittent iron and folic acid supplementation during pregnancy.. http://www.who.int/ elena/titles/intermittent_iron_pregnancy/en/.

5. World Health Organisation. WHO recommendations on antenatal care for a positive pregnancy experience. Organisation $\mathrm{WH}$, ed. Geneva: who, 2016

6. Hanieh S, Ha TT, Simpson JA, et al. The effect of intermittent antenatal iron supplementation on maternal and infant outcomes in rural Viet Nam: a cluster randomised trial. PLoS Med 2013;10:e1001470.

7. Pena-Rosas JP, De-Regil LM, Garcia-Casal MN, et al. Daily oral iron supplementation during pregnancy. Cochrane Database Syst Rev 2015;7:CD004736.

8. Hanieh S, Ha TT, Simpson JA, et al. The effect of intermittent antenatal iron supplementation on maternal and infant outcomes in rural Viet Nam: a cluster randomised trial. PLoS Med 2013;10:e1001470.

9. United Nations Childrens Fund. A review of the nutrition situation in Vietnam 2009-2010. UNCs F, ed. Ha Noi, 2011.
10. United Nations Children's Fund WHO, United Nations University. Composition of a multi-micronutrient supplement to be used in pilot programmes among pregnant women in developing countries. report of a UNICEF/WHO/UNU Workshop. New York: United Nations Children's Fund, 1999.

11. World Health Organisation. The WHO Child Growth Standards. Geneva: World Health Organisation, 2006.

12. World Health Organisation. WHO Anthro (version 3.2.2, January 2011) and macros. secondary WHO Anthro (version 3.2.2, January 2011) and macros. ;2011 http://www.who.int/childgrowth/software/ en/.

13. Scholl TO. Maternal iron status: relation to fetal growth, length of gestation, and iron endowment of the neonate. Nutr Rev 2011;69:S23-S29.

14. Kitsiou-Tzeli S, Tzetis M. Maternal epigenetics and fetal and neonatal growth. Curr Opin Endocrinol Diabetes Obes 2017;24:1

15. Belkacemi L, Nelson DM, Desai M, et al. Maternal undernutrition influences placental-fetal development. Biol Reprod 2010;83:325-31.

16. Devakumar D, Chaube SS, Wells JC, et al. Effect of antenatal multiple micronutrient supplementation on anthropometry and blood pressure in mid-childhood in Nepal: follow-up of a double-blind randomised controlled trial. Lancet Glob Health 2014;2:e654-e663.

17. Khan Al, Kabir I, Ekström EC, et al. Effects of prenatal food and micronutrient supplementation on child growth from birth to 54 months of age: a randomized trial in Bangladesh. Nutr $\mathrm{J}$ 2011:10:134.

18. Zhou J, Zeng L, Dang S, et al. Maternal Prenatal Nutrition and Birth outcomes on malnutrition among 7- to 10-Year-Old children: a 10Year Follow-Up. J Pediatr 2016;178:40-6.

19. Stewart CP, Christian P, LeClerq SC, et al. Antenatal supplementation with folic acid + iron + zinc improves linear growth and reduces peripheral adiposity in school-age children in rural Nepal. Am J Clin Nutr 2009;90:132-40.

20. Roberfroid D, Huybregts L, Lanou H, et al. Impact of prenatal multiple micronutrients on survival and growth during infancy: a randomized controlled trial. Am J Clin Nutr 2012;95:916-24.

21. Vaidya A Saville N, Shrestha BP, et al. Effects of antenatal multiple micronutrient supplementation on children's weight and size at 2 years of age in Nepal: follow-up of a double-blind randomised controlled trial. Lancet 2008;371:492-9.

22. Wang $\mathrm{W}$, Yan $\mathrm{H}$, Zeng L, et al. No effect of maternal micronutrient supplementation on early childhood growth in rural western China: 30 month follow-up evaluation of a double blind, cluster randomized controlled trial. Eur J Clin Nutr 2012;66:261-8.

23. Christian P, Kim J, Mehra S, et al. Effects of prenatal multiple micronutrient supplementation on growth and cognition through $2 \mathrm{y}$ of age in rural Bangladesh: the JiVitA-3 trial. Am J Clin Nutr 2016;104:1175-82.

24. Prado EL, Dewey KG. Nutrition and brain development in early life. Nutr Rev 2014;72:267-84.

25. Li C, Zeng L, Wang D, et al. Prenatal Micronutrient Supplementation is not associated with Intellectual Development of Young SchoolAged Children. J Nutr 2015;145:1844-9.

26. Christian P, Murray-Kolb LE, Khatry SK, et al. Prenatal micronutrient supplementation and intellectual and motor function in early schoolaged children in Nepal. JAMA 2010;304:2716-23.

27. Prado EL, Alcock KJ, Muadz H, et al. Maternal multiple micronutrient supplements and child cognition: a randomized trial in Indonesia. Pediatrics 2012;130:e536-e546.

28. Tofail F, Persson LA, El Arifeen S, et al. Effects of prenatal food and micronutrient supplementation on infant development: a randomized trial from the maternal and Infant Nutrition Interventions, Matlab (MINIMat) study. Am J Clin Nutr 2008;87:704-11.

29. Li Q, Yan H, Zeng L, et al. Effects of maternal multimicronutrient supplementation on the mental development of infants in rural western China: follow-up evaluation of a double-blind, randomized, controlled trial. Pediatrics 2009;123:e685-e692.

30. Devakumar D, Fall CH, Sachdev HS, et al. Maternal antenatal multiple micronutrient supplementation for long-term health benefits in children: a systematic review and meta-analysis. BMC Med 2016;14:90 